\title{
St John Simpson. "The Land behind Ctesiphon: The Archaeology of Babylonia during the Period of the Babylonian Talmud"
}

\section{Rémy Boucharlat}

\author{
(2) OpenEdition \\ Journals \\ Édition électronique \\ URL : http://journals.openedition.org/abstractairanica/45919 \\ DOI : 10.4000/abstractairanica.45919 \\ ISBN : 1961-960X \\ ISSN : 1961-960X \\ Éditeur : \\ CNRS (UMR 7528 Mondes iraniens et indiens), Éditions de l'IFRI
}

\section{Référence électronique}

Rémy Boucharlat, «St John Simpson. "The Land behind Ctesiphon: The Archaeology of Babylonia during the Period of the Babylonian Talmud" », Abstracta Iranica [En ligne], Volume 37-38-39 | 2018, document 28, mis en ligne le 30 décembre 2018, consulté le 02 octobre 2020. URL : http://

journals.openedition.org/abstractairanica/45919; DOI : https://doi.org/10.4000/abstractairanica 45919

Ce document a été généré automatiquement le 2 octobre 2020.

Tous droits réservés 


\title{
St John Simpson. "The Land behind Ctesiphon: The Archaeology of Babylonia during the Period of the Babylonian Talmud"
}

\author{
Rémy Boucharlat
}

\section{RÉFÉRENCE}

St John Simpson. "The Land behind Ctesiphon: The Archaeology of Babylonia during the Period of the Babylonian Talmud" in Markham J. Geller (ed.). The Archaeology and Material Culture of the Babylonian Talmud. Leiden: Brill, 2015, p. 6-38.

1 Les données matérielles et descriptions contenues dans le Bavli (le Talmud babylonien des VIe-VIIe s. de n.è.) concernant Ctésiphon (la Veh-Ardashir/ Mahoza, fondée par Ardeshir I) sont importantes pour reconstruire l'organisation et la vie dans la ville. L'A. confronte des éléments du texte aux données archéologiques fournies surtout par les fouilles italiennes des années 1960-70 à Veh Ardeshir /Choche, la ville circulaire. Le contenu du texte tend à améliorer l'image de la cité qui devait avoir l'aspect d'une ville orientale aux constructions en briques crues, à l'urbanisme moins organisé que celui de la Séleucie-du-Tigre antérieure fondée par les Séleucides, avec des maisons accolées souvent modestes, sans étage, des commerces et des suq.

2 La Mésopotamie centrale et méridionale n'a pas été étudiée aussi finement pour l'époque sassanide qu'elle l'a été pour les périodes très antérieures, de sorte que le matériel archéologique, principalement issu des prospections, est difficilement utilisable pour reconstituer la société et l'économie dans les campagnes à cette époque. Le peuplement est très probablement bien supérieur aux estimations proposées avant les années 1980 ; de même le réseau de canaux y était plus dense que les estimations anciennes et servait non seulement à l'irrigation, mais aussi au transport des denrées 
(céréales, figues, dates, vin, etc.) et bien d'autres fruits et légumes très divers, comme l'indique le Bavli. Les artisanats très variés sont bien attestés par les textes mais, à l'exception de la céramique et du verre, les autres matériaux, surtout les restes organiques et même le métal, sont peu ou pas conservés dans les prospections de surface.

\section{AUTEURS}

\section{RÉMY BOUCHARLAT}

UMR 5133 CNRS-Université de Lyon 